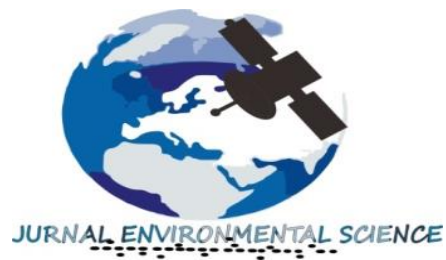

Jurnal EnvironmentaI Science

Volume 1 Nomor 1 Oktober 2018.

p-ISSN : 2654-4490 dan e-ISSN : 0000-0000

Homepage at : ojs.unm.ac.id/JES

E-mail:jes@unm.ac.id

\title{
Persepsi Masyarakat Terhadap Perubahan Budaya di Tana Toraja (Studi Kasus Upacara Rambu Tuka')
}

\author{
Abdul Rahmad \\ Jurusan Geografi, Fakultas Matematika dan Ilmu Pengetahuan Alam,
}

Universitas Negeri Makassar, 2018, Indonesia.

\begin{abstract}
The purpose of this study is to find out: 1) what factors influence the shift in the values of the Rambu Tuka 'ceremony in Toraja, and 2) to find out how the cultural values of Rambu Tuka' in the Toraja are shifted. This study aims to determine what factors influence the shift in the values of the Rambu Tuka 'ceremony in Toraja. Knowing the shift in the cultural values of Rambu Tuka in Toraja. The collection of data using the method of observation, interviews and documentation. So that the results of the study show that out of all the results outline the factors that cause cultural changes in Toraja are caused by many factors. Factors that greatly influence the shift in cultural values of tuka signs in tana toraja are; Modern technology, and other cultural influences. So from that it can be concluded that the public perception of the cultural changes that exist in Toraja, is not much different from each respondent's opinion. For the generations of Toraja youth, Let us maintain the culture that has developed in the community such as the Ruka Tuka 'ceremony, so that values contained such as togetherness, help, and cooperation are maintained considering that one of the great potentials for tourism is in the culture of Tana Toraja.
\end{abstract}

Keywords: Shift, Value, Culture, Rambu Tuka,

\begin{abstract}
ABSTRAK
Tujuan penelitian ini yaitu untuk mengetahui: 1) faktor - faktor apa saja yang mempengaruhi pergeseran nilai-nilai upacara Rambu Tuka' di Toraja, dan 2) untuk mengetahui bagaimana pergeseran nilai-nilai budaya Rambu Tuka' di Toraja. Penelitian ini bertujuan untuk mengetahui Faktor - faktor apa saja yang mempengaruhi pergeseran nilai-nilai upacara Rambu Tuka' di Toraja. Mengetahui pergeseran nilai-nilai budaya Rambu Tuka' di Toraja. Adapun pengumpulan data dengan metode observasi, wawancara dan dokumentasi. Sehingga hasil penelitian menunjukkan bahwa dari semua hasil secara garis besar Faktor penyebab perubahan budaya yang ada di toraja di sebabkan oleh banyak faktor. Faktor yang sangat berpengaruh terhadap pergeseran nilai-nilai budaya rambu tuka' di tana toraja yaitu; Teknologi modern, dan pengaruh budaya lain. Maka dari itu dapat disimpulkan bahwa persepsi masyarakat terhadap perubahan budaya yang ada di Toraja, tidak jauh berbeda pendapat dari tiap responden.Untuk generasi-generasi muda Toraja, Mari kita menjaga kebudayaan yang telah berkembang dalam masyarakat seperti upacara Rambu Tuka', agar nilai-nilai yang terkandung seperti kebersamaan, tolong menolong, dan kerjasama tetap terjaga mengingat bahwa salah satu potensi yang besar untuk pariwisata terdapat pada kebudayaan Tana Toraja.
\end{abstract}

Kata Kunci : Pergeseran, Nilai, Budaya, Rambu Tuka' 


\section{PENDAHULUAN}

Sebelum agama masuk ke Toraja, masyarakat Toraja hidup dalam aturan aluk todolo atau lebih sering disebut dengan alukta. Alukta merupakan aturan tata hidup pada masyarakat Toraja yang berkenaan dengan sistem pemerintahan, sistem kemasyarakatan dan sistem kepercayaan. Sesuai kepercayaan aluk todolo, masyarakat Toraja mengenal keberadaan tiga oknum yang memiliki kendali atas kehidupan manusia, yakni Puang Matua, deata, dan to membali Puang. Kebudayaan berasal dari bahasa sansekerta yaitu buddhayah, yang merupakan bentuk jamak dari buddhi (budi atau akal) diartikan sebagai hal-hal yang berkaitan dengan budi dan akal manusia (Maran, 2007 ) .

Rambu Tuka' adalah kata dalam Bahasa Toraja yang secara harafiah berarti asap yang naik atau arahnya ke atas, artinya asap persembahan itu naik ke langit sebelum matahari mencapai zenit. Rambu Tuka' sering juga disebut aluk rampe matallo, ritusritus di sebelah timur. Persembahanpersembahan

tersebut dialamatkan kepada para dewa dan kepada para leluhur yang sudah menjadi dewa, yang sekarang dipercaya mendiami langit sebelah timur laut. Ritus-ritus dalam rambu tuka' dimaknai sebagai sebuah bentuk permohonan untuk mendapatkan berkat dan segala kebutuhan hidup di dunia ini. Beberapa ritus yang termasuk ke dalam Rambu Tuka' adalah Ma' Bua', Merok, Mangrara Banua, dan Rampanan Kapa' (Theodorus Kobong, 2008).

\section{Konsep nilai}

Dalam realitas sosial kehidupan bersama, manusia memerlukan aturan hidup agar tercipta keteraturan sosial. Aturan hidup tersebut tidak selalu diwujudkan secara nyata, tetapi terdapat dorongan dari diri manusia unutk melakukan atau tidak melakukan sesuatu. Sosiologi memandang nilai-nilai sebagai pengertian-pengertian (sesuatu di dalam kepada orang) tentang baik tidaknya perbuatan-perbuatan. Dengan kata lain, nilai adalah hasil penilaian atau pertimbangan moral. Nilai erat kaitannya dngan kebudayaan dan masyarakat. Setuap masyarakat atau kebudayaan memiliki nilainilai tertentu mengenai sesuatu. Kebudayaan dan masyarakat itu sendiri merupakan nilai yang tidak terhingga bagi orang yang memilikinya.

2. Kebudayaan

Kebudayaan berasal dari bahasa sangsekerta yakni "budhaya", sebagai bentuk jamak dari budhi yang berarti budi atau akal. Kebudayaan dapat dikatakan sebagai hal yang bersangkutan dengan budi dan akal. (koentjaraningrat kadir 1992) beliau merumuskan defenesi kebudayaan itu sebagai "keseluruhan gagasan dan karya seni manusia yang harus dibiasakan dalam belajar beserta keseluruhan dari hasil budi dan karyanya..

3. Upacara Rampanan Kapa'/Perkawinan

Ikatan pernikahan merupakan sesuatu yang dianggap sakral atau suci sehingga terkadang pernikahan diartikan juga sebuah perayaaan cinta di mana dalam peristiwa tersebut terjadi pengukuhan hubungan antara dua insan baik secara agama maupun hukum. Menikah juga bukan hanya menyatukan dua pribadi saja, tetapi juga dua keluarga, sehingga dengan mengadakan pesta pernikahan dianggap sebagai ungkapan rasa syukur, kebahagiaan dan kebanggaan tersendiri.

4. Konsep Perubahan Budaya Rambu Tuka'

Masyarakat senantiasa berubah di semua tingkat kompleksitas internalnya. Di tingkat makro terjadi perubahan ekonomi, politik dan kultur. 
Di tingkat mezzo terjadi perubahan kelompok, komunitas dan organisasi. Sedangkan di tingkat mikro terjadi perubahan interaksi dan perilaku individu. Seperti yang dikatakan Edward Shils, "masyarakat adalah fenomena antarwaktu. Masyarakat terjelma bukan karena keberadaannya di suatu perjalanan waktu. Tetapi ia hanya ada melalui waktu. Ia adalah jelmaan waktu. (1981; 327). Menurut Edward, masyarakat bukan sebuah kesatuan fisik (entity), melainkan seperangkat proses yang saling terkait bertingkat ganda.

\section{METODE PENELITIAN}

Penelitian ini bersifat deskriptif kualitatif dengan menggunakan pendekatan fenomenologi. Pengumpulan data dilakukan dengan metode observasi secara langsung ke lapangan dan wawancara untuk mengumpulkan informasi (data primer), namun didukung oleh referensi lain (data sekunder) untuk melengkapi data yang tidk sempat diperoleh oleh peneliti di lokasi penelitian.

Metode pengambilan data dalam penelitian kualitatif sangat beragam, hal ini disebabkan karena sifat penelitian kualitatif terbuka dan luwes, tipe dan metode pengumpulan data dalam penelitian ini sangat beragam, disesuaikan dengan masalah, tujuan penelitian, serta sifat objek yang diteliti.

\section{HASIL DAN PEMBAHASAN}

Dari hasil penelitian di lapangan, perubahan yang terjadi khusus dalam pelaksanaan upacara adat rambu tuka', merupakan perubahan yang tidak dikehendaki, di mana perubahan tersebut berlangsung di luar jangkauan pengawasan masyarakat sehingga menyebabkan timbulnya akibat-akibat sosial yang tidak diharapkan.

Seiring dengan perkembangan zaman, budaya Rambu Tuka' yang ada di Toraja mengalami perkembangan dan perubahan. Dimulai dari budaya tradisional, budaya peralihan, hingga budaya modern. Perubahan budaya merupakan suatu kejadian yang terjadi dalam kehidupan di dunia ini. Perubahan budaya sendiri adalah adanya ketidak sesuaian di antara unsurunsur budaya yang saling berbeda, sehingga terjadilah keadaan yang tidak sesuai dengan fungsinya bagi kehidupan.

Perubahan budaya yang terjadi dalam suku Toraja tidak luput dari faktor-faktor yang mempengaruhi. Menurut $\mathrm{T}$ Tambuku (71) faktor -faktor penyebab perubahan tersebut terbagi menjadi 2, yaitu faktor intern dan faktor ekstern..

\section{Faktor intern}

Merupakan faktor yang berasal dari masyarakat itu sendiri yang menyebabkan perubahan budaya, yang diantaranya:

a. Adanya kontak dengan kebudayaan lain

b. Sistem pendidikan formal yang maju

c. Sikap menghargai hasil karya orang lain

d. Sistem lapisan masyarakat yang terbuka

e. Penduduk yang heterogen

f. Ketidakpuasan masyarakat terhadap bidang-bidang kehidupan tertentu

g. Memiliki orientasi ke masa depan

h. Nilai bahwa manusia harus selalu berusaha memperbaiki hidup..

\section{Faktor ekstern}

Merupakan faktor yang berasal dari luar masyarakat melalui interaksi sosial yang mendorong terjadinya suatu perubahan budaya, yang diantaranya:
a. Pengaruh lingkungan fisik alam
b. Peperangan
c. Masuknya budaya masyarakat lain
d. Masuknya agama lain 
Proses modernisasi dalam hal ini bisa dikatakan bersifat kompleks dan global karena perubahan atau pergeserannya melalui banyak cara dan mempengaruhi semua manusia. Ada yang melalui kemajuan pendidikan, ada yang melalui penerapan teknologi yang canggih, semua atas harapan bagi kesejahteraan hidup manusia.

Proses pelaksanaan rampanan kapa' zaman dulu yaitu sebagai berikut ;

a. Umpalingka kada (menyampaikan niat). Umba Pangngan atau mengantar sirih pinang dilaksanakan pada malam hari, karena pantang bagi keluarga yang akan menikahkan anaknya ketika diketahui oleh masyarakat. Sirih pinang yang hendak diantarkan ke pihak perempuan disediakan oleh pihak yang dituakan oleh utusan laki-laki dengan kriteria bahwa buah pinang (kalosi) umumnya langsung diambil di dekat rumah karena pada umumnya masyarakat masingmasing memiliki pohon pinang di sekitar rumahnya. Buah pinang (kalosi) dipetik dengan cara dipanjat untuk memastikan bahwa buah pinang tersebut masih mudah dan masih utuh serta lengkap dengan penutupnya. Buah sirih (bolu), karena jarang masyarakat yang menanam. Buah sirih tersebut harus lengkap dengan tangkai buahnya atau tangkai daunnya. Kapur (kapu') umumnya dibikin sendiri oleh masyarakat jika bahannya kebetulan ada (dalam bahasa setempat disebut suso kapu'). Jika semua sudah lengkap (Kalosi, bolu, kapu', sambako') maka dibungkus rapi menggunakan pelepah pinang kemudian diikat erat dan dibungkus sarung dan dililit di badan utusan yang dipercayakan.

b. Dipakendek atau Rampo Bannang, Setelah mengantarkan sirih pinang, tahap selanjutnya adalah peresmian lamaran yang disebut Rampo Bannang atau Dipakendek yang juga dilaksanakan pada malam hari. Disebut Rampo Bannang atau Dipakendek karena pada tahap ini adalah peresmian lamaran secara adat dari pihak laki-laki kepada pihak perempuan dengan menyajikan makanan berupa nasi dan ikan saja (ketika masih ada hubungan keluarga), namun ketika mereka sudah tidak memiliki hubungan keluarga maka yang di sajikan adalah nasi dan pa'piong (daging babi yang di masak dalam bambu). Pada tahap ini yang sangat menarik adalah jika tiba acara makan bersama calon pengantin laki-laki bersama utusannya dan juga keluarga perempuan menyantap makanan bersama, sedangkan calon pengantin perempuan berdiam diri di bagian selatan rumah tongkonan menunggu calon pengantin laki-laki selesai menyantap makanannya dan di sisahkan ke calon pengantin perempuan untuk di makan. Tujuan hal ini dilakukan adalah agar nantinya jika mereka sudah menikah, istri harus tunduk kepada suami.

c. Ma' Kapa' Allo, Tahap ini adalah tahap inti dari upacara perkawinan pada masyarakat Nanggala berdasarkan kepercayaan Aluk Todolo. tahap ini dilaksanakan dari pagi sampai siang dan sudah dihadiri oleh keluarga bahkan masyarakat. Pada tahap ini berbeda dengan tahap sebelumnya dimana pada tahap ini babi sudah banyak yang di kurbankan untuk menjamu tamu yang hadir.

Dari hasil penelitian yang penulis dapatkan bahwa perubahan tahapan-tahapan dalam proses upacara adat rambu tuka' 
khususnya pada Rampanan Kapa' (perkawinan) pada masa sekarang sudah berbeda dengan yang dulu. Adapun tahapantahapan prosesi pernikahan yang penulis dapatkan yaitu;

1. Menyampaikan Adanya kesepakatan antara laki-laki dan perempuan untung melangsungkan acara lamaran. Yang mana biasanya laki-laki yang langsung datang ke rumah perempuan dengan menyampaikan niat untuk melamar dan mengatur jadwal kapan sang laki-laki datang membawa keluarganya ke rumah perempuan tersebut.

2. setelah tanggal yang ditentukan tiba, sang laki-laki membawa keluarganya ke rumah perempuan. Setelah sampai di rumah perempuan, sebelum pintu rumah di buka akan ada balas pantun antara perwakilan laki-laki dan perempuan.

3. Setelah keluarga laki-laki masuk ke rumah perempuan akan ada balas pantun lagi dari pihak laki-laki dan perempuan dengan tujuan maksud kedatangannya ke tempat perempuan.

4. Perkenalan keluarga dari semua pihak yang ada. Biasanya dipimpin oleh juru bicara sang perempuan.

5. Penentuan tanggal resepsi pernikahan dan pembahasan seputar pernikahan yang akan di langsungkan ke depan, baik berupa tempat dan lain sebagainya.

6. Resepsi pernikahan

Perubahan sosial berkenaan dengan perubahan unsur-unsur sosial dalam masyarakat yang menimbulkan ketidaksesusaian suatu pola kehidupan dalam masyarakat dengan fungsinya. Unsurunsur ini meliputi pola perilaku, interaksi sosial, norma yang mengaturnya. Berubahnya sistem norma dan nilai dalam masyarakat, berubah pula pola perilaku dan interaksi sosialnya, baik antar individu maupun antar kelompok. Perubahan budaya meliputi ide-ide dan gagasan, kepercayaan, etos budaya, pandangan hidup, nilai serta sistem pengetahuan.

Sebuah perubahan terjadi pasti ada yang melatarbelakangi sehingga menjadi suatu peristiwa. Seperti halnya dengan perubahan yang terjadi dalam upacara rambu tuka'. Perubahan ini merupakan perubahan yang tidak dikehendaki atau direncanakan karena waktu perubahannya tidak diketahu jelas. Perubahan ini merupakan pengaruh dari kehadiran modernisasi yang mana nilai-nilai dala upacara adat rambu tuka', tergeser oleh nilai-nilai yang dibawa oleh modernisasi tersebut.

Sesuai dengan hasil penelitian, mulai dari observasi dan wawancara langsung ke lapangan, penulis dapat menyimpulkan bahwa sistem sosial dalam masyarakat atau warga Toraja sudah tidak sesuai fungsinya.

Sesuai dengan lima prinsip pokok yang dipaparkan oleh Stephen K. Sanderson, di mana masyarakat merupakan sistem yang kompleks yang terdiri dari bagian-bagian yang saling berhubungan dan saling tergantung dan saling berpengaruh secara signifikan terhadap bagian-bagiannya.

Pergeseran nilai yang terjadi dalam pelaksanaan upacara adat rambu tuka' dapat dikatakan termasuk dalam perubahan yang tidak dikehendaki, di mana perubahan tersebut terjadi di luar jangkauan pengawasan masyarakat dan yang menyebabkan timbulnya akibat-akibat sosial yang tidak diharapkan. Akibat- sosial yang terjadi seperti perubahan pola tingkah laku, nilai-nilai yang dianut sebelumnya yang sudah tidak lagi diindahkan, khususnya dalam pelaksanaan upacara adat rambu tuka'. 


\section{KESIMPULAN}

1. Faktor penyebab perubahan budaya yang ada di toraja di sebabkan oleh banyak faktor. Faktor yang sangat berpengaruh terhadap perbuahan budaya yaitu; Teknologi modern, dan pengaruh budaya lain. Dan seiring berjalan waktu penulis yakin bahwa apabila adat dan budaya toraja tidak mulai di pelihara dari sekarang maka beberapa tahun kedepan budaya Toraja akan sirna di telan oleh zaman modern.

2. Dari semua hasil yang telah diperoleh penulis maka dapat disimpulkan bahwa bentuk pergeseran nilai terhadap perubahan budaya yang ada di Toraja, tidak jauh berbeda pendapat dari tiap informan. Penulis menyimpulkan bahwa perubahan budaya yang ada di Toraja sangat signifikan. Artinya bahwa budaya yang ada di Toraja sangat memprihatinkan karena masyarakat yang ada di toraja itu sendiri tidak mengetahui bagaimana sebenarnya budaya Toraja itu sendiri. Budaya toraja yang dulu dan sekarang sangatlah berbeda dan mungkin tidak seiring berkembangnya zaman budaya Toraja akan hilang apabila tidak ada usaha dari masyarakat Toraja untuk mempertahankan budayanya sendiri.

\section{DAFTAR PUSTAKA}

Maran, Rafael 2007. Manusia dan kebudayaan . pt ribeka cipta Jakarta.

Theodorus Kobong. 2008. Injil dan Tongkonan. Jakarta: BPK Gunung Mulia. Hal. 54-64.

Koentjaraningrat. 2009. Pengantar Ilmu Antropologi . Jakarta: Rineka Cipta.

Syarif, E., Sumarmi, S., Fatchan, A., \& Astina, I. K. 2016. Integrasi Nilai Budaya Etnis Bugis Makassar Dalam
Proses Pembelajaran Sebagai Salah Satu Strategi Menghadapi Era Masyarakat Ekonomi Asean (MEA). Jurnal Teori dan Praksis Pembelajaran IPS, 1(1), 13 21.

Syarif, E., Hasriyanti, H., Fatchan, A., Astina, I. K., \& Sumarmi, S. (2016). Conservation Values Of Local Wisdom Traditional Ceremony Rambu Solo Toraja's Tribe South Sulawesi As Efforts The Establishment Of Character Education. EFL JOURNAL, 1(1), 17-23.

Syarif, E., Fatchan, A., \& Astina, K. 2016. Tradition of" Pasang Ri-Kajang" in the Forests Managing in System Mores of" Ammatoa" at District Bulukumba South Sulawesi, Indonesia. Mediterranean Journal of Social Sciences, 7(6), 325.

Syarif, E. 2017. Studi Fenomenologi Makna Pasang ri Kajang dalam Pengelolaan Hutan Masyarakat Adat Ammatoa Bulukumba Sulawesi Selatan. DISERTASI dan TESIS Program Pascasarjana UM.

Syarif, E. 2017. Environmental Management in Local Wisdom Perspective of Karampuang People, Sinjai District, South Sulawesi. Sainsmat, 6(2). 
A. Rahmad: Persepsi Masyarakat Terhadap Perubahan Budaya. 